\title{
Oxidative stress in pregnancy and fertility pathologies
}

\begin{abstract}
Oxidative stress designates the state of imbalance between reactive oxygen species (ROS) production and antioxidant levels. In a healthy placenta, there is an increase in ROS production, due to formation of new tissues and inherent metabolism, but this is balanced by higher levels of antioxidants. However, this balance is lost in some situations, with a consequent increase in oxidative stress levels. Oxidative stress has been implicated in several placental disorders and pregnancy pathologies. The present review intends to summarize what is known about the relationship between oxidative stress and well-known pregnancy disorders.
\end{abstract}

Keywords Oxidative stress $\cdot$ Placenta $\cdot$ Pregnancy disorders $\cdot$ Reactive oxygen species

\section{Oxidative stress}

Oxidative stress is the term used to designate an imbalance between reactive oxygen species (ROS) and anti- oxidant levels in a cell, favoring the former (Burton and Jauniaux 2011; Dalle-Donne et al. 2006; Dröge 2002; Halliwell 2003). ROS include free-radical intermediates such as superoxide anion radical $\left(\mathrm{O}_{2}{ }^{-}\right.$; the most abundant under physiological conditions (Burton and Jauniaux 2011)), hydroxyl radical (HO·), peroxyl radical (ROO), alkoxyl radical (RO·), and hydroperoxyl radical $\left(\mathrm{HO}_{2}\right)$, and non-radical intermediates such as hydrogen peroxide $\left(\mathrm{H}_{2} \mathrm{O}_{2}\right)$, ozone $\left(\mathrm{O}_{3}\right)$, hypochlorous acid $(\mathrm{HOCl})$, peroxynitrite (ONOO-), and singlet oxy- gen $\left({ }^{1} \mathrm{O}_{2}\right)$. These compounds have high instability due to the existence of one or more, unpaired electrons (Aherne and O’Brien 2000; Dalle-Donne et al. 2003; Valko et al. 2007). ROS can be generated from multiple mechanisms. Some of its sources include the following:
\& Normal metabolic reactions such as redox reactions during cell respiration. $\mathrm{O}_{2}$ reduction to water implies a 1-2 \% electron leakage, generating $\mathrm{O}_{2} \cdot{ }^{-}$at the ubiquinone and NADH dehydrogenase (complex I) level, as well as in complex III;

\& Radiation, exciting UV rays, and ionizing X rays;

\& Xenobiotics and drug metabolism;

\& The activity of monoamine oxidase, which deaminates biogenic amines. This mechanism occurs at the outer membrane of the mitochondria and is associated to large $\mathrm{H}_{2} \mathrm{O}_{2}$ production;

\& In purine catabolism and formation of uric acid, in the reactions catalyzed by xanthine oxidase, a $\mathrm{O}_{2} \cdot{ }^{-}$-producing enzyme (Myatt and Cui 2004);

\& In the reactions catalyzed by xanthine oxidoreductase, nicotinamide adenine dinucleotide phosphate $(\mathrm{NAD}(\mathrm{P}) \mathrm{H})$ oxidase, nitric oxide synthase, and heme oxygenase, and in the formation of peroxynitrite (Myatt and Cui 2004);

\& during an inflammatory response, the production of $\mathrm{H}_{2} \mathrm{O}_{2}$ and $\mathrm{O}_{2}{ }^{-{ }^{-} \text {greatly }}$ increases in cells such as polymorphonuclear cells, eosinophils, monocytes, Kupffer cells, and macrophages, thanks to a highly specialized NAD(P)H-dependent oxidase system located in the outer surface of the cell membrane, coupled to the action of superoxide dismutase (SOD) (Burton and Jauniaux 2011; Poli et al. 2004);

\& during protein folding taking place in the endoplasmic reticulum, where a significant amount of $\mathrm{O}_{2}{ }^{-}$is formed. In this process, the formation of disulfide bonds is an oxidative process, since it involves the oxidation of sulfhydryl groups of cysteine residues (Burton and Jauniaux 2011; Burton et al. 2009; Poli et al. 2004). 
ROS measurement is difficult because of high reactivity, very short half-life, and low concentrations. Therefore, indirect markers such as malondialdehyde are commonly used to evaluate secondary products of ROS damage.

At homeostatic levels, ROS are implicated in diverse actions on cell function, including activation of redoxsensitive transcription factors and activation of protein kinases (Burton and Jauniaux 2011), regulation of vascular tone and functions controlled by $\mathrm{O}_{2}$ concentrations, enhancement of signal transduction from many membrane receptors (e.g., the antigen receptor of lymphocytes) (Dröge 2002), combating pathogens (Myatt and Cui 2004), among others. However, when in excess, ROS can induce cell injury and a chronic inflammatory state that can trigger a cascade of free-radical reactions, promoting secondary ROS generation and resulting in cellular modification and damage in DNA, carbohydrates, proteins, and polyunsaturated fatty acids. This oxidative injury follows a general pattern that involves free thiol oxidation and formation of disulfide proteins, depletion of the ATP pool, free cytosolic $\mathrm{Ca}^{2+}$ increment, disintegration of cytoskeleton, increase in membrane lipid peroxidation, release of cytosolic compounds, and DNA damage (Aherne and O'Brien 2000; DalleDonne et al. 2006; Poston et al. 2011). Examples of human conditions associated with increased oxidative state include cellular aging, brain dysfunction and neurodegenerative diseases, cancer, diabetes, rheumatoid arthritis, and cardiovascular and renal diseases (Dröge 2002; Mitjavila and Moreno 2012; Silva and Soares-daSilva 2007; Valko et al. 2007).

Oxidative stress and the placenta

In a healthy placenta, there is an increase in oxidative stress levels, due to a high placental mitochondrial activity resulting in an increase in ROS production (Myatt and Cui 2004). However, this is accompanied by an increase in antioxidant protection (such as the activity of the enzymes superoxide dismutase, catalase, and glutathione peroxidase), which compensates for the in- crease in ROS production
(Coughlan et al. 2004b). In this way, the balance between ROS and antioxidants stays preserved.

During normal placental development, ROS seem to have important roles. In the first trimester, placental $\mathrm{O}_{2}$ levels are relatively low, with a pressure around $20 \mathrm{mmHg}$ (Tuuli et al. 2011), due to lack of established maternal intraplacental circulation, which is believed to be the reason why the embryo is particularly protected from ROS at that time. These low $\mathrm{O}_{2}$ levels are essential for normal cell proliferation and placental angiogenesis, promoted by hypoxia-induced transcriptional and posttranscriptional regulation of angiogenic factors such as vascular endothelial growth factor and placental growth factor (Tuuli et al. 2011). However, once maternal intraplacental circulation is fully established (toward the end of the first trimester), the $\mathrm{O}_{2}$ tension triples and, with it, so does ROS levels, particularly at the syncytiotrophoblastic layer (Burton and Jauniaux 2011; Burton et al. 2010). The placenta then adapts to this increase by modulating hypoxia-inducible factor $1 \alpha$ (HIF-1 $\alpha)$ and increasing cellular antioxidant levels (Tuuli et al. 2011). Under normal conditions, this adaptation is favorable to fetal development. For example, some studies suggest that $\mathrm{NAD}(\mathrm{P}) \mathrm{H}$ oxidase can act as an "oxygen sensor," regulating differentiation of cytotrophoblasts into syncytiotrophoblasts when $\mathrm{O}_{2}$ tension increases, and vascular endothelial growth factor A (VEGF-A) and metalloproteins are sensitive to oxidative stress (Poston and Raijmakers 2004). Also, super- oxide activates cytokine synthesis and, therefore, much probably plays a role in the maternal inflammatory state that characterizes a normal pregnancy (Poston and Raijmakers 2004).

As mentioned above, increased oxidative stress is inherent to increased ROS levels observed in a normal pregnancy. However, in a scenario where oxidative stress is abnormally increased, damage affecting both the mother and the fetus can be observed. Several studies have been conducted for the last two decades that relate increased oxidative stress levels to several pregnancy pathologies, including gestational diabetes mellitus, spontaneous abortion, idiopathic recurrent pregnancy loss, defective embryogenesis, drug- induced teratogenicity, preeclampsia, intrauterine growth restriction, and minor congenital abnormalities, as well as to future diseases in adulthood such as obesity, diabetes mellitus, and hypertension 
(Burton et al. 2009, 2010; Dröge 2002; Hempstock et al. 2003; Myatt 2010; Poston et al. 2011; Shibata et al. 2010; Theuerkauf et al. 2010; Tuuli et al. 2011).

Over the next sections, the relationship between oxidative stress and well-known pregnancy pathologies will be presented.

Oxidative stress and pregnancy disorders

Gestational diabetes mellitus (GDM)

GDM is a type of diabetes mellitus where a healthy pregnant woman develops glucose intolerance of varying severity (Coughlan et al. 2004b). Although it was classically estimated to develop in 2-5\% of pregnancies, according to the new International Association of the Diabetes and Pregnancy Study Groups (IADPSG) Consensus Panel diagnostic criteria, the prevalence has significantly increased to about $18 \%$ of all pregnancies (Sacks et al. 2012). GDM develops around the second half of gestation (by the time the placental villi undergoes extensive angiogenesis and vascularization) and has a significant role in fetal macrosomia, perinatal mortality, and long-term risk of developing type 2 diabetes mellitus for the mother, which is why it is considered a "pre-diabetic" state (Coughlan et al. 2004b; Gauster et al. 2012; Myatt and Cui 2004).

In diabetes mellitus, ROS are thought to be produced in excess as a result of prolonged periods of exposure to hyperglycemia, which is known to cause nonenzymatic glycation of plasma proteins (Myatt and Cui 2004). Glucose undergoes auto-oxidation, forming freeradical hydroxilic anions which overwhelm the antioxidant cellular responses. So, the high blood glucose levels affect the surrounding vasculature, causing the endothelium to be more sensitive to free radicals (Leach et al. 2009). Several studies have identified increased levels of biomarkers of ROS damage and abnormalities in the antioxidant defenses in diabetic patients (Coughlan et al. 2004b). For instance, carbonylated proteins, one of the most used markers of protein oxidation as a result of oxidative stress, are found in significantly higher levels in erythrocyte membranes in individuals with type 2 diabetes mellitus and correlates with impaired glycemic control (Coughlan et al. 2004b).
In relation to GDM, both the placental protein carbonyl content and the release of 8-isoprostane (8IP), a stable and sensitive indicator of in vivo lipid peroxidation, were found to be greater when compared to healthy pregnant women (Coughlan et al. 2004b). This was associated with an increased activity and gene expression of antioxidant enzymes such as catalase, glutathione reductase, and CuZn-SOD (AlShebly and Mansour 2012; Coughlan et al. 2004b; Lappas et al. 2010). Additionally, adaptation to exogenous oxidative stress was tested in placental tissues from women with and without GDM, in order to investigate if women with GDM would be less responsive to oxidative stress. Interestingly enough, based on the analysis of 8-IP and tumor necrosis factor alpha (TNFa) release and nuclear factor-kappaB (NF$\mathrm{KB})$ activity and on the analysis of cytokine release and antioxidant enzyme activity (catalase and glutathione reductase), respectively, both studies concluded that GDM placenta have a reduced capacity to respond to exogenous oxidative stress (Coughlan et al. 2004b; Lappas et al. 2010), mediated by a repression of NF-KB (Coughlan et al. 2004a). In contrast, a very recent study did not find differences in both oxidative stress biomarkers (malondialdehyde (MDA) and protein carbonyls) and antioxidant capacity (GSSG, reduced glutathione (GSH) and glutathione peroxidase) between control and GDM placentas (Araújo et al. 2013). However, as stressed by the authors, the reason for the apparent discrepancy relates to the fact that women in the GDM group were diagnosed according to the new IADPSG criteria (Sacks et al. 2012), which encompass women with a less severe diabetic phenotype. For most of the abovementioned studies, GDM women were treated by controlled nutrition and/or insulin administration.

The use of antioxidant therapy in GDM has been investigated in the past. Antioxidant administration was found to decrease oxidative stress levels and increase antioxidant capacity (Asemi et al. 2013; Cederberg et al. 2001; Ley et al. 2013; Liang et al. 2009; Lorenzoni et al. 2013; Makni et al. 2011; Sakamaki et al. 1999; Wentzel and Eriksson 2005; Yessoufou et al. 2006) and to decrease fasting blood glucose, insulin resistance, and inflammation (Asemi et al. 2013; Ley et al. 2013; Liang et al. 2009). 
Importantly, antioxidant therapy was able to attenuate or prevent diabetic complications (e.g., malformations) in the offspring (Badr et al. 2011; Cederberg et al. 2001; Eriksson and Simán 1996; Sakamaki et al. 1999; Simán and Eriksson 1997a,

b; Sugimura et al. 2009; Wentzel and Eriksson 2005). So, antioxidant intake appears to be able to attenuate GDM complications in the offspring.

Intrauterine growth restriction

Intrauterine growth restriction (IUGR) is a pregnancy disorder where the fetus does not develop to full growth in the womb (Burton and Jauniaux 2011). The ideal diagnosis seems to be divided in a two-stage process: restriction of the growth by ultrasonography and use of transcerebellar diameter when gestational age is questionable (Mandruzzato et al. 2008). Despite being a multifactorial etiology pathology (Mandruzzato et al. 2008), most cases with no genetic or infectious cause are thought to be related to a compromised maternal blood circulation to the placenta, based on high- resistance uterine arterial waveforms and morphological studies of the spiral arteries (Burton and Jauniaux 2011), associated with deregulation of villous vasculogenesis and abundant fibrin deposition (Scifres and Nelson

2009). IUGR is associated with increased risk of fetal mortality and morbidity (Garite et al. 2004) and predisposes children to an increased risk of hypertension, cardiovascular disorders, and renal diseases in adult- hood (Scifres and Nelson 2009).

Several studies have been conducted in order to evaluate the relationship between IUGR and oxidative stress. In particular, one study evaluated four parameters of cell membrane injury (MDA, Schiff bases, lipid peroxides, and conjugated dienes) in plasma and blood samples, and a correlation between IUGR and an increase in these membrane-damage parameters was found, suggesting a role of ROS in this pathology (Karowicz-Bilińska et al. 2002). Also, oxidative stress biomarkers (MDA and protein oxidation) were evaluated in erythrocytes from both mother and fetus, and in both, oxidative stress markers were significantly in- creased in IUGR pregnancies (Kamath et al. 2006). In another study, oxidative stress biomarkers such as lipid peroxidation, protein, and DNA damage as well as antioxidant enzyme activity like glutathione peroxidase, superoxide dismutase, and catalase were evaluated in neonates with
IUGR. The IUGR group showed de- creased antioxidant levels, leading toward the conclusion that neonates with IUGR have significant deficiency in antioxidant defenses and significant increased lipid peroxidation (Hracsko et al. 2008). The same conclusions were found regarding different oxidative stress biomarkers, namely, malondialdehyde (MDA) and xanthine oxidase (XO) (Biri et al. 2007), leading to the general conclusion that increased oxidative stress and IUGR are correlated.

When a mixture of antioxidants (vitamin C, cocarboxylase, and solcoseryl) was administered to pregnant women with IUGR, a decrease in various oxidative stress biomarkers (e.g., lipid peroxides) was observed (Karowicz-Bilińska et al. 2002). Still, no correlation between antioxidant therapy and IUGR prevention has been reported.

\section{Preeclampsia}

Preeclampsia (PE), which affects 2-14 \% of all pregnancies and occurs primarily in nulliparous women in the third trimester, is a clinical syndrome of systemic inflammatory response, characterized by hypertension (blood pressure higher than 140/90 $\mathrm{mmHg}$ ) and either proteinuria (>300 $\mathrm{mg} / 24 \mathrm{~h}$ ) or endorgan dysfunction (central nervous system dysfunction, hepatic abnormality, thrombocytopenia, renal abnormality, pulmonary edema) after 20 weeks of gestation in a previously normotensive woman (Agarwal et al. 2012; Burton and Jauniaux 2011; Roberts et al. 2013; Myatt and Cui 2004; Poston et al. 2011). PE can have an early-onset development, when it is manifested before 34 weeks of gestation, or a late onset, if it develops after the 34th week of gestation (Agarwal et al. 2012). One of the basic pathological events is maternal vascular endothelial injury, which may favor the production of vasoconstrictors, resulting in vasospasms, very common in PE (Agarwal et al. 2012; Fujimaki et al. 2011).

The exact etiology and pathogenesis of PE is still unclear due to its non-specific symptoms. Nevertheless, there are many common maternal hallmarks in PE, such as a generalized arteriolar constriction and intravascular depletion, which can produce symptoms related to ischemia, necrosis, and hemorrhage of organs and result in poor perfusion of the maternal and fetal circulations of the placenta, shallow trophoblast invasion, significantly increased neutrophilendothelial 
adhesion and adhesion molecule expression, and abnormal increase in production of TNFa, a cytokine produced mainly by macrophages, among others (Myatt and Cui 2004). Also, an increase in protein carbonyls, lipid peroxides, nitrotyrosine residues, and DNA oxidation (common biomarkers of oxidative stress) has been associated with PE (Agarwal et al. 2012; Burton and Jauniaux 2011).

So, although the cause of PE remains largely unknown, oxidative stress and a generalized inflammatory state are features of this disease. The placenta appears to be the principal source of free-radical synthesis, but the maternal leukocytes and the maternal endothelium are also likely contributors (Raijmakers et al. 2004). Different hypothesis relate increased placental oxidative stress levels and PE. The first one is the vascular hypothesis, because early-onset PE is associated with a deficient conversion of the spiral arteries, and it has been proposed that failure in this conversion results in intermittent perfusion of the placenta and a low-grade ischemia-reperfusion type injury (Agarwal et al. 2012; Burton and Jauniaux 2011). Hypoxiareoxygenation in vitro is a potent inducer of oxidative stress in term placental explants, much more than hypoxia alone, and it has been shown that exposure of explants to changes in oxygenation causes generation of ROS within the trophoblast and endothelial cells as well as the formation of nitrotyrosine residues, in a pattern matching closely to that seen in PE placentas (Burton and Jauniaux 2011). Another hypothesis relates to $\mathrm{NAD}(\mathrm{P}) \mathrm{H}$ oxidase, which is responsible for generating and sensing oxidative stress levels. The oxidase activity was detected and confined to the $\mathrm{m}$ icrovillus me mbrane of syncytiotrophoblast and might be abnormally regulated in PE pregnancies (Myatt and Cui 2004). However, more studies need to be conducted. Another hypothesis, that complements the first one mentioned above, suggests that ROS are related to $\mathrm{PE}$ because there is a developmental failure in oxygen handling by the trophoblasts, since maximal placental trophoblast invasion occurs at the end of the first trimester, when oxygen pressure increases abruptly (Myatt and Cui 2004). Hypoxiareoxygenation was found to cause apoptosis of syncytiotrophoblasts, which can be related with a shallow trophoblast invasion and consequently to increased ROS levels observed in PE. Oxidative stress can cause increased nitration of p38MAPK, inducing its catalytic activity and, in this way, cause a poor implantation and the growth restriction observed in $\mathrm{PE}$
(Agarwal et al. 2012).

Several distinct oxidative stress-related biomolecules have been found to be altered in PE placenta, including increased levels of oxidative stress biomarkers such as MDA and 4-hydroxynonenal (4-HNE), increased formation of nitrotyrosine, of xanthine oxidase activity, and of autoantibodies against the angiotensin AT1 receptor, which stimulate $\mathrm{NAD}(\mathrm{P}) \mathrm{H}$ oxidase activity, leading to an increase in ROS production and in the synthesis of many placental factors, including microparticulate apoptotic debris, proinflammatory cytokines, and angiogenic factors (Agarwal et al. 2012; Burton and Jauniaux 2011; Takagi et al. 2004). For example, in cultured trophoblasts and smooth muscle cells, the AT1 receptor of PE women seems to promote $\mathrm{NAD}(\mathrm{P}) \mathrm{H}$ oxidase overexpression (Agarwal et al. 2012). However, none of these mentioned factors are systematically present in all cases of PE, which means that the real cause of this disorder might yet to be discovered or that it does not depend on only one parameter.

Early-onset PE is almost invariably associated with IUGR (Burton and Jauniaux 2011). Despite having distinctive clinical manifestations, there is accumulating evidence that the two pathologies have a common cause: an abnormal placental implantation (Mert et al. 2012). Several studies have been conducted in order to understand if the two pathologies are related (Fujimaki et al. 2011; Mert et al. 2012; Takagi et al. 2004; Wiktor et al. 2004). One study, using immunohistochemistry and Western blotting in tissue samples from normal and $\mathrm{PE}$ placentas, suggested that the oxidative damage was higher in placenta displaying PE together with IUGR when compared with placenta displaying PE alone (Takagi et al. 2004). Another study measured 8hydroxydeoxyguanosine $(8-\mathrm{OHdG})$, which is another well-established marker for DNA oxidative damage, to evaluate the oxidative damage in placental samples of normal, PE, and PE plus IUGR pregnant women. The PE plus IUGR group presented the highest $8-\mathrm{OHdG}$ levels, with a significant difference from control. The PE group, however, showed no statistically significant difference from control (Wiktor et al. 2004). Other studies on the same subject showed similar conclusions, with oxidative stress levels being higher in the groups that exhibit both pathologies (Fujimaki et al. 2011; Mert et al. 2012). These findings suggest a correlation be- tween the severity of the deficiency in the interaction 
between cytotrophoblasts and the maternal spiral arteries, both representative of IUGR and PE, and the levels of oxidative stress (Wiktor et al. 2004).

A Cochrane review (including 10 trials and 6,533 women) assessed the effect of an antioxidant regimen in $\mathrm{PE}$; in the majority of trials, the antioxidant regimen assessed was a combination of vitamins $\mathrm{C}$ and $\mathrm{E}$. Of note, there was no significant difference between antioxidant and control groups for PE or any other primary outcome: severe PE, preterm birth before 37 weeks, small-for-gestational-age infants, or any perinatal death. So, evidence from this review does not support routine antioxidant supplementation during pregnancy to reduce the risk of PE and other complications in pregnancy (Poston et al. 2011; Ruder et al. 2008).

Spontaneous miscarriage and recurrent pregnancy loss

Spontaneous abortion can be characterized by an unintentional pregnancy termination, before the fetus is considered viable or, in alternative, when the fetus' weight is less than $500 \mathrm{~g}$. It has an incidence of 8-20 $\%$ of all pregnancies and is mainly a result of chromosomal abnormality, which accounts for $50 \%$ of all miscarriages. The remaining $50 \%$ are related to congenital and uterine abnormalities, infections, maternal diseases, and idiopathic causes (Agarwal et al. 2012).

By using an $\mathrm{O}_{2}$ probe in women with pregnancy termination before the end of the first trimester, a steep rise in placental $\mathrm{O}_{2}$ pressure between gestation weeks 8 and 12 , coincident with the establishment of maternal blood perfusion of the early placenta, was found. In the same study, an increase in oxidative stress biomarkers, such as MDA and lipid peroxides, was observed in placental tissue from early pregnancy losses compared with controls, despite upregulation of antioxidants such as catalase, glutathione peroxidase, and $\mathrm{Cu} / \mathrm{Zn}$ and $\mathrm{Mn}$ superoxide dismutase. The authors suggested that increased ROS may result from a premature and abrupt establishment of maternal placental perfusion (Poston et al. 2011). By contrast, other studies also suggested that the oxidative damage to the trophoblast induced by premature and widespread onset of the maternal placental circulation is a key factor in early pregnancy loss, but the premature oxidative stress increase was concluded to result from the lack of antioxidant levels to neutralize the increased levels of ROS (Burton and Jauniaux 2011; Jauniaux et al. 2003; Myatt and Cui 2004).
Despite the differences observed in the mentioned studies, there seems to be a correlation between an unbalance of ROS and antioxidant levels and miscarriage. Therefore, an abnormal placentation resulting in damage of syncytiotrophoblasts may explain the in- creased sensitivity of the latter to oxidative stress during the first trimester, which may contribute to idiopathic recurrent pregnancy loss (Agarwal et al. 2012).

Nevertheless, antioxidants intake and miscarriage prevention does not seem to have a correlation. Indeed, although obstetricians have been using vitamin $E$ for years in the hope of preventing abortion (SHUTE 1960), there is no evidence that taking antioxidant vitamin supplements, alone or in combination with other agents, prior to pregnancy or in early pregnancy, prevents miscarriage (Rumbold et al. 2005). So, further studies are needed.

ROS and fertility-related diseases

Endometriosis

Endometriosis is a benign, estrogen-dependent, chronic, complex, and multifactorial gynecological disorder characterized by the presence of endometrial tissue outside the uterus (Augoulea et al. 2009; Giudice and Kao 2004). This pathology, which may interfere with the ovulation process and cause tubal occlusion (Ruder et al. 2008), affects women in reproductive age and is associated with pelvic pain and infertility (Giudice and Kao 2004; Gupta et al. 2006).

Although little is known regarding this pathophysiology, ROS seem to be associated with increased growth and adhesion of endometrial cells to the peritoneal cavity, leading to endometriosis (Jackson et al. 2005). In several independent studies regarding this pathology and oxidative stress biomarkers, peritoneal fluid from women suffering from endometriosis was found to have increased levels of MDA, 8-OHdG, 8oxoguanine DNA glycosylase, protein carbonyls, interleukin-6, TNFa, interleukin-1 $\beta$, interleukin-8, VEGF, and 8-iso- prostangladin F2-alpha (8-isoPGF2a) (Andrade et al.2010; Carvalho et al. 2013; Matsuzaki and Schubert2010; Mier-Cabrera et al. 2011; Montuschi et al. 2004; Morrow et al. 1992; Rong et al. 2002; Sharma et al.2010). Furthermore, 8iso-PGF2a levels were concluded to be useful in predicting oxidative status in diseases such as endometriosis (Montuschi et al. 2004; Morrow et al. 1992; Sharma et al. 2010). Moreover, a heat shock 
protein 70 (HSP70) family member (HSP70b'), known to be present under increased oxidative conditions, has been found in high concentrations in the blood of patients with this pathology (Lambrinoudaki et al. 2009). Also, lower levels of antioxidants such as vitamins $\mathrm{A}, \mathrm{C}, \mathrm{E}$, zinc, and copper were found in women with endometriosis (Mier-Cabrera et al. 2009). Finally, vitamin E levels were significantly decreased in patients with endometriosis before the beginning of ovulation induction, perhaps due to the fact that antioxidants are consumed during oxidation reactions. Moreover, after ovulation induction with exogenous gonadotropins, patients with endometriosis presented increased lipid peroxidation and maintained lower vitamin E levels, a fact that hypothetically could compromise oocyte quality in endometriotic patients. However, on the day of oocyte retrieval, both serum lipid peroxidation potential and vitamin E levels were found similar in both groups (Campos Petean et al. 2008).

The accumulating data thus correlate oxidative stress in the peritoneal cavity and the pathogenesis of endometriosis (Polak and Kotarski 2010) and conclude that oxidative stress as a biomarker of cell injury seems to be a reliable quantitative test of endometriosis severity (Carvalho et al. 2013).

Some studies evaluated the effect of antioxidant therapy for endometriosis treatment. A high antioxidant diet, containing vitamins A, C, and E, originated an increase in antioxidant enzyme activity as well as a decrease in oxidative stress markers after 2 months of intervention (Mier-Cabrera et al. 2009). Moreover, ad- ministration of antioxidants (vitamin $\mathrm{C}$ and $\mathrm{E}$ ) was concluded to reduce chronic pelvic pain and inflammatory markers in the peritoneal fluid in women with endometriosis (Santanam et al. 2013). All these findings suggest that a diet rich in antioxidants may help diminish endometriosis symptoms.

\section{Polycystic ovary syndrome (PCOS)}

PCOS is characterized by a number of conditions such as chronic anovulation, enlarged cystic ovaries, hyperandrogenism, infertility, and often insulin resistance (Agarwal et al. 2012; Ruder et al. 2008), despite its definition and etiology still being controversial (Radomski et al. 2007). Women with PCOS present difficulties in becoming pregnant and often experience spontaneous abortion, along with menstrual and skin disorders (Agarwal et al. 2012; Ruder et al. 2008), as well as increased risk of gestational diabetes mellitus, hypertension, and preeclampsia during pregnancy (Boomsma et al. 2006; Roos et al. 2011).

PCOS has been associated with increased ROS levels, mainly due to a decrease of the antioxidant capacity. One study suggested that PCOS independently influences oxidative stress, by measurement of total oxidant status and total antioxidant capacity (Blair et al. 2013). Also, PCOS in neonates was found to be associated with their mothers' oxidative status (Boutzios et al. 2013). Moreover, a correlation between insulin resistance, oxidative stress biomarker levels such as malondialdehyde, and PCOS was observed in nonobese women (Kurdoglu et al.

2012; Macut et al. 2011) and between mitochondrial dysfunction, by decrease in $\mathrm{O}_{2}$ consumption and in GSH levels, and PCOS were found in polymorphonuclear cells (Victor et al. 2011). Finally, in some studies, the correlation between PCOS and oxidative stress seems to be more evident in obese women (Liu and Zhang 2012).

Interestingly enough, the antioxidant $\mathrm{N}$ acetylcysteine was found to be a safe and welltolerated adjuvant to clomiphene citrate for improvement of ovulation and pregnancy rates in PCOS patients (Badawy et al. 2007; Nasr 2010; Rizk et al. 2005; Salehpour et al. 2012). Moreover, controlledrelease alpha lipoic acid has positive effects on PCOS phenotype, although its effects may be exerted through a mechanism not involving changes in oxidative stress (Masharani et al. 2010).

\section{Idiopathic infertility}

Idiopathic infertility is usually diagnosed by exclusion and can be described as the inability to conceive during a 1-year period without use of any kind of protection during intercourse; it affects around $15 \%$ of couples in USA (Agarwal et al. 2012; Ruder et al. 2008).

Regarding oxidative stress and idiopathic infertility, increased levels of ROS, and in particular of ROS biomarkers such as MDA, were found in this condition (Polak et al. 1999, 2001b), but this increase seems to result from decreased levels of antioxidants (GSH, $\alpha$ tocopherol, selenium) (Agarwal et al. 2012; Wang et al. 1997). Since the sperm is highly sensitive to oxidative stress, these results led to the hypothesis that peritoneal fluids having higher concentrations of ROS and lower 
antioxidant capacity by diffusing into the fallopian tubes could damage the sperm and thus block possible fecundation (Polak et al. 2001a).

Moreover, oocyte quality is also affected by oxidative stress. During the first meiotic phase in the oocyte, as well in the folliculogenesis, a low level of ROS is required. So, it is expected that under excessive ROS levels, an impairment of oocyte maturation may occur in meiosis II, which, together with an inadequate intracellular antioxidant capacity, will limit a successful ovulation and fertilization (Poston et al. 2011). Despite this, the results in these studies were obtained with a limited number of women and, therefore, require further investigation.

\section{Fertility decline}

Each month, the process of oocyte growth and development involves meiosis I, which is targeted by an in- crease in ROS and inhibited by antioxidants, and meiosis II, which is promoted by antioxidants, suggesting a complex relationship between ROS and oxidative stress/ antioxidants in the ovary. Also, the increase in steroid production in the growing follicle causes an increase in cytochrome P450 activity, resulting in increased ROS formation, which is an important inducer of ovulation (Agarwal et al. 2012).

Aging of the oocytes (a decrease in oocyte quality with aging) affects many biochemical

Table 1 Summary of major changes in oxidative stress levels, antioxidant activity, and oxidative stress biomarkers in pregnancy and fertility diseases

\begin{tabular}{|c|c|c|}
\hline Pathology & $\begin{array}{l}\text { Changes in oxidative stress levels and oxidative stress } \\
\text { biomarkers }\end{array}$ & References \\
\hline GDM & $\begin{array}{l}\text { - Increased carbonylated proteins and 8-IP levels } \\
\text { - Increased activity and gene expression of antioxidant } \\
\text { enzymes }\end{array}$ & $\begin{array}{l}\text { Al-Shebly and Mansour 2012; Coughlan et al. 2004b; } \\
\text { Lappas et al. } 2010\end{array}$ \\
\hline IUGR & $\begin{array}{l}\text { - Increased levels of MDA, Schiff bases, lipid } \\
\text { peroxides, conjugated dienes, and protein oxidation } \\
\text { - Significant deficiency in antioxidant defenses }\end{array}$ & $\begin{array}{l}\text { Biri et al. 2007; Burton and Jauniaux 2011; Hracsko et al. } \\
\text { 2008; Kamath et al. 2006; Karowicz-Bilińska et al. } \\
\text { 2002; Scifres and Nelson } 2009\end{array}$ \\
\hline PE & $\begin{array}{l}\text { - Increased levels of MDA, 8-OHdG, and 4-HNE } \\
\text { - Increased nitration of p38MAPK } \\
\text { - Increased formation of nitrotyrosine and of } \\
\text { autoantibodies against angiotensin AT1 receptor } \\
\text { - NAD(P)H oxidase overexpression } \\
\text { - Increased XO activity }\end{array}$ & $\begin{array}{l}\text { Agarwal et al. 2012; Burton and Jauniaux 2011; Mert } \\
\text { et al. 2012; Fujimaki et al. 2011; Mert et al. 2012; } \\
\text { Takagi et al. 2004; Wiktor et al. } 2004\end{array}$ \\
\hline $\begin{array}{l}\text { Spontaneous } \\
\text { miscarriage and } \\
\text { recurrent pregnancy } \\
\text { loss }\end{array}$ & $\begin{array}{l}\text { - Increased levels of MDA and lipid peroxides } \\
\text { - Significant deficiency in antioxidant defenses }\end{array}$ & $\begin{array}{l}\text { Agarwal et al. 2012; Burton and Jauniaux 2011; Jauniaux } \\
\text { et al. 2003; Myatt and Cui 2004; Poston et al. } 2011\end{array}$ \\
\hline Endometriosis & $\begin{array}{l}\text { - Increased levels of MDA, 8-OHdG, protein carbonyls, } \\
\text { IL6, TNFa, IL1 } \beta \text {, IL8, VEGF, 8-iso-PGF2a, } \\
\text { HSP70, and lipid peroxidation } \\
\text { - Low antioxidants levels }\end{array}$ & $\begin{array}{l}\text { Andrade et al. 2010; Campos Petean et al. 2008; Carvalho } \\
\text { et al. 2013; Matsuzaki and Schubert 2010; Mier- } \\
\text { Cabrera et al. 2011; Montuschi et al. 2004; Morrow } \\
\text { et al. 1992; Rong et al. 2002; Sharma et al. } 2010\end{array}$ \\
\hline PCOS & $\begin{array}{l}\text { - Increased MDA levels } \\
\text { - Decrease in antioxidant capacity }\end{array}$ & Blair et al. 2013; Kurdoglu et al. 2012; Macut et al. 2011 \\
\hline Idiopathic infertility & $\begin{array}{l}\text { - Increased MDA levels } \\
\text { - Decreased levels of antioxidants (GSH, } \alpha \text {-tocopherol, } \\
\text { selenium) }\end{array}$ & Agarwal et al. 2012; Wang et al. 1997 \\
\hline Fertility decline & $\begin{array}{l}\text { - Increase in damaged DNA, 8-OHdG } \\
\text { - Increased ROS-mediated damage }\end{array}$ & Agarwal et al. 2012; Tarín et al. 2000; Salmon et al. 2010 \\
\hline
\end{tabular}

GDM gestational diabetes, 8-IP 8-isoprostane, IUGR intrauterine growth restriction, MDA malondialdehyde, 8-OHdG 8hydroxydeoxyguanosine, 4-HNE 4-hydroxynonenal, XO xanthine oxidase, IL6 interleukin-6, TNF $\alpha$ tumor necrosis factor alpha, IL1 $\beta$ interleukin-1 $\beta$, IL8 interleukin-8, VEGF vascular endothelial growth factor, 8-iso-PGF2 $\alpha$ 8-iso-prostangladin F2-alpha, HSP70 heat shock protein 70 , PCOS polycystic ovary syndrome 
pathways important for the implantation process and development of the embryo (Tarín et al. 2000). Recent studies have shown that lowquality oocytes contain increased amounts of damaged DNA and chromosomal aneuploidy, secondary to age-related dysfunctions (Agarwal et al. 2012). Most degenerative changes undergone by oocytes during aging may be explained by freeradical-mediated damage, with the mitochondrial electron transport chain being a major source of ROS (Tarín et al. 2000). In one study, 8-OHdG (8hydroxydeoxyguanosine) levels were found to be higher in aging oocytes. $8-\mathrm{OHdG}$, an oxidized derivative of deoxyguanosine, is the most common base modification in mutagenic damage and is used as a biomarker of OS (Salmon et al. 2010).

\section{Conclusions}

Whether there are extensive facts or only recent studies in need of further investigation, the relationship between oxidative stress and pregnancy pathologies seem to be clear (Table 1). ROS can negatively affect all different stages of pregnancy and thus contribute to the development of pathologies such as gestational diabetes mellitus, IUGR, PE, miscarriage, and spontaneous abortion, as well as fertility-related diseases, although the mechanisms by which ROS play such a significant role in the course of pregnancy remain not very well defined. Still, it is clear that placental oxidative stress is a multifactorial process that implicates several and distinctive outcomes, with different degrees of severity, depending on the mothers' previous health and genetic predisposal, as well as on environment conditions.

There is emerging enthusiasm in the use of antioxidants, and natural or synthetic molecules that mimic antioxidant enzymes are the new tools being developed (Agarwal et al. 2005). However, at present, there is little convincing evidence that antioxidant supplements can improve fertility or prevent miscarriage or PE. Nevertheless, the range of strategies attempted so far has not been extensive, and there is good evidence that wellconducted, adequately powered trials involving other approaches would be of value (Poston et al. 2011).

\section{References}

Agarwal A, Gupta S, Sharma RK. Role of oxidative stress in female reproduction. Reprod Biol Endocrinol. 2005;3:28.

Agarwal A, Aponte-Mellado A, Premkumar BJ, Shaman A, Gupta $\mathrm{S}$. The effects of oxidative stress on female reproduction: a review. Reprod Biol Endocrinol. 2012;10:49.

Aherne SA, O'Brien NM. Mechanism of protection by the flavonoids, quercetin and rutin, against tert-butylhydroperoxideand menadione-induced DNA single strand breaks in Caco-2 cells. Free Radic Biol Med. 2000;29:507-14.

Al-Shebly MM, Mansour MA. Evaluation of oxidative stress and antioxidant status in diabetic and hypertensive women during labor. Oxid Med Cell Longev. 2012;2012:329743.

Andrade, A.Z., J.K. Rodrigues, L.A. Dib, G.S. Romão, R.A. Ferriani, A.A. Jordão Junior, and P.A. Navarro. Serum markers of oxidative stress in infertile women with endometriosis. Rev Bras Ginecol Obstet. 2010;32:279-285.

Araújo JR, Ramalho C, Correia-Branco A, Faria A, Ferraz T, Keating E, et al. A parallel increase in placental oxidative stress and antioxidant defenses occurs in pre-gestational type 1 but not gestational diabetes. Placenta. 2013;34:1095-8.

Asemi Z, Samimi M, Tabassi Z, Sabihi SS, Esmaillzadeh A. A randomized controlled clinical trial investigating the effect of DASH diet on insulin resistance, inflammation, and oxidative stress in gestational diabetes. Nutrition. 2013;29:619-24.

Augoulea A, Mastorakos G, Lambrinoudaki I, Christodoulakos G, Creatsas G. The role of the oxidative-stress in the endometriosis-related infertility. Gynecol Endocrinol. 2009;25:75-81.

Badawy A, State O, Abdelgawad S. N-acetyl cysteine and clomiphene citrate for induction of ovulation in polycystic ovary syndrome: a cross-over trial. Acta Obstet Gynecol Scand. 2007;86:218-22.

Badr G, Alwasel S, Ebaid H, Mohany M, Alhazza I. Perinatal supplementation with thymoquinone improves diabetic complications and $\mathrm{T}$ cell immune responses in rat offspring. Cell Immunol. 2011;267:133-40.

Biri A, Bozkurt N, Turp A, Kavutcu M, Himmetoglu O, Durak I. Role of oxidative stress in intrauterine growth restriction. Gynecol Obstet Invest. 2007;64:187-92.

Blair SA, Kyaw-Tun T, Young IS, Phelan NA, Gibney J, McEneny J. Oxidative stress and inflammation in lean and obese subjects with polycystic ovary syndrome. J Reprod Med. 2013;58:107-14.

Boomsma CM, Eijkemans MJ, Hughes EG, Visser GH, Fauser BC, Macklon NS. A meta-analysis of pregnancy outcomes in women with polycystic ovary syndrome. Hum Reprod Update. 2006; 12:673-83.

Boutzios G, Livadas S, Piperi C, Vitoratos N, Adamopoulos C, Hassiakos D, et al. Polycystic ovary syndrome offspring display increased oxidative stress markers comparable to gestational diabetes offspring. Fertil Steril. 2013;99:943-50.

Burton GJ, Jauniaux E. Oxidative stress. Best Pract Res Clin Obstet Gynaecol. 2011;25:287-99.

Burton, G.J., H.W. Yung, T. Cindrova-Davies, and D.S. CharnockJones. Placental endoplasmic reticulum stress and oxidative stress in the pathophysiology of unexplained intrauterine growth restriction and early onset preeclampsia. Placenta. 2009;30 Suppl A:S43-48. 
Burton GJ, Jauniaux E, Charnock-Jones DS. The influence of the intrauterine environment on human placental development. Int J Dev Biol. 2010;54:303-12.

Campos Petean C, Ferriani RA, dos Reis RM, de Moura MD, Jordão AA, Navarro PA. Lipid peroxidation and vitamin E in serum and follicular fluid of infertile women with peritoneal endometriosis submitted to controlled ovarian hyperstimulation: a pilot study. Fertil Steril. 2008;90:2080-5.

Carvalho LF, Abrão MS, Biscotti C, Sharma R, Nutter B, Falcone $\mathrm{T}$. Oxidative cell injury as a predictor of endometriosis progression. Reprod Sci. 2013;20:688-98.

Cederberg J, Simán CM, Eriksson UJ. Combined treatment with vitamin $\mathrm{E}$ and vitamin $\mathrm{C}$ decreases oxidative stress and improves fetal outcome in experimental diabetic pregnancy. Pediatr Res. 2001;49:755-62.

Coughlan MT, Permezel M, Georgiou HM, Rice GE. Repression of oxidant-induced nuclear factor-kappaB activity mediates placental cytokine responses in gestational diabetes. J Clin Endocrinol Metab. 2004a;89:3585-94.

Coughlan MT, Vervaart PP, Permezel M, Georgiou HM, Rice GE. Altered placental oxidative stress status in gestational diabetes mellitus. Placenta. 2004b;25:78-84.

Dalle-Donne I, Rossi R, Giustarini D, Milzani A, Colombo R. Protein carbonyl groups as biomarkers of oxidative stress. Clin Chim Acta. 2003;329:23-38.

Dalle-Donne I, Rossi R, Colombo R, Giustarini D, Milzani A. Biomarkers of oxidative damage in human disease. Clin Chem. 2006;52:601-23.

Dröge W. Free radicals in the physiological control of cell function. Physiol Rev. 2002;82:47-95.

Eriksson UJ, Simán CM. Pregnant diabetic rats fed the antioxidant butylated hydroxytoluene show decreased occurrence of malformations in offspring. Diabetes. 1996;45:1497-502.

Fujimaki A, Watanabe K, Mori T, Kimura C, Shinohara K, Wakatsuki A. Placental oxidative DNA damage and its repair in preeclamptic women with fetal growth restriction. Placenta. 2011;32:367-72.

Garite TJ, Clark R, Thorp JA. Intrauterine growth restriction increases morbidity and mortality among premature neonates. Am J Obstet Gynecol. 2004;191:481-7.

Gauster M, Desoye G, Tötsch M, Hiden U. The placenta and gestational diabetes mellitus. Curr Diab Rep. 2012;12:16-23.

Giudice LC, Kao LC. Endometriosis. Lancet. 2004;364:1789-99.

Gupta S, Agarwal A, Krajcir N, Alvarez JG. Role of oxidative stress in endometriosis. Reprod Biomed Online. 2006;13: 126-34.

Halliwell B. Oxidative stress in cell culture: an under-appreciated problem? FEBS Lett. 2003;540:3-6.

Hempstock J, Jauniaux E, Greenwold N, Burton GJ. The contribution of placental oxidative stress to early pregnancy failure. Hum Pathol. 2003;34:1265-75.

Hracsko Z, Orvos H, Novak Z, Pal A, Varga IS. Evaluation of oxidative stress markers in neonates with intra-uterine growth retardation. Redox Rep. 2008;13:11-6.

Jackson LW, Schisterman EF, Dey-Rao R, Browne R, Armstrong D. Oxidative stress and endometriosis. Hum Reprod. 2005;20:2014-20.

Jauniaux E, Gulbis B, Burton GJ. Physiological implications of the materno-fetal oxygen gradient in human early pregnancy. Reprod Biomed Online. 2003;7:250-3.
Kamath U, Rao G, Kamath SU, Rai L. Maternal and fetal indicators of oxidative stress during intrauterine growth retardation (IUGR). Indian J Clin Biochem. 2006;21:111-5.

Karowicz-Bilińska A, Suzin J, Sieroszewski P. Evaluation of oxidative stress indices during treatment in pregnant women with intrauterine growth retardation. Med Sci Monit. 2002;8: 211-6.

Kurdoglu Z, Ozkol H, Tuluce Y, Koyuncu I. Oxidative status and its relation with insulin resistance in young non-obese women with polycystic ovary syndrome. J Endocrinol Invest. 2012;35:317-21.

Lambrinoudaki IV, Augoulea A, Christodoulakos GE, Economou EV, Kaparos G, Kontoravdis A, et al. Measurable serum markers of oxidative stress response in women with endometriosis. Fertil Steril. 2009;91:46-50.

Lappas M, Mitton A, Mittion A, Permezel M. In response to oxidative stress, the expression of inflammatory cytokines and antioxidant enzymes are impaired in placenta, but not adipose tissue, of women with gestational diabetes. J Endocrinol. 2010;204:75-84.

Leach L, Taylor A, Sciota F. Vascular dysfunction in the diabetic placenta: causes and consequences. J Anat. 2009;215:69-76.

Ley SH, Hanley AJ, Sermer M, Zinman B, O'Connor DL. Lower dietary vitamin $\mathrm{E}$ intake during the second trimester is associated with insulin resistance and hyperglycemia later in pregnancy. Eur J Clin Nutr. 2013;67:1154-6.

Liang HY, Hou F, Ding YL, Zhang WN, Huang XH, Zhang BY, et al. Clinical evaluation of the antioxidant activity of astragalus in women with gestational diabetes. Nan Fang Yi Ke Da Xue Xue Bao. 2009;29:1402-4.

Liu J, Zhang D. The role of oxidative stress in the pathogenesis of polycystic ovary syndrome. Sichuan Da Xue Xue Bao Yi Xue Ban. 2012;43:187-90.

Lorenzoni F, Giampietri M, Ferri G, Lunardi S, Madrigali V, Battini L, et al. Lutein administration to pregnant women with gestational diabetes mellitus is associated to a decrease of oxidative stress in newborns. Gynecol Endocrinol. 2013;29:901-3.

Macut D, Simic T, Lissounov A, Pljesa-Ercegovac M, Bozic I, Djukic T, et al. Insulin resistance in nonobese women with polycystic ovary syndrome: relation to byproducts of oxidative stress. Exp Clin Endocrinol Diabetes. 2011;119:451-5.

Makni M, Sefi M, Garoui EM, Fetoui H, Boudawara T, Zeghal N. Dietary polyunsaturated fatty acid prevents hyperlipidemia and hepatic oxidant status in pregnant diabetic rats and their macrosomic offspring. J Diabetes Complications. 2011;25: 267-74.

Mandruzzato G, Antsaklis A, Botet F, Chervenak FA, Figueras F, Grunebaum A, et al. Intrauterine restriction (IUGR). J Perinat Med. 2008;36:277-81.

Masharani U, Gjerde C, Evans JL, Youngren JF, Goldfine ID. Effects of controlled-release alpha lipoic acid in lean, nondiabetic patients with polycystic ovary syndrome. J Diabetes Sci Technol. 2010;4:359-64.

Matsuzaki S, Schubert B. Oxidative stress status in normal ovarian cortex surrounding ovarian endometriosis. Fertil Steril. 2010;93:2431-2.

Mert I, Oruc AS, Yuksel S, Cakar ES, Buyukkagnici U, Karaer A, et al. Role of oxidative stress in preeclampsia and intrauterine growth restriction. J Obstet Gynaecol Res. 2012;38:658-64. 
Mier-Cabrera J, Aburto-Soto T, Burrola-Méndez S, JiménezZamudio L, Tolentino MC, Casanueva E, et al. Women with endometriosis improved their peripheral antioxidant markers after the application of a high antioxidant diet. Reprod Biol Endocrinol. 2009;7:54.

Mier-Cabrera J, Jiménez-Zamudio L, García-Latorre E, CruzOrozco O, Hernández-Guerrero C. Quantitative and qualitative peritoneal immune profiles, T-cell apoptosis and oxidative stress-associated characteristics in women with minimal and mild endometriosis. BJOG. 2011;118:6-16.

Mitjavila MT, Moreno JJ. The effects of polyphenols on oxidative stress and the arachidonic acid cascade. Implications for the prevention/treatment of high prevalence diseases. Biochem Pharmacol. 2012;84:1113-22.

Montuschi P, Barnes PJ, Roberts LJ. Isoprostanes: markers and mediators of oxidative stress. FASEB J. 2004;18:1791-800.

Morrow JD, Awad JA, Boss HJ, Blair IA, Roberts LJ. Noncyclooxygenase-derived prostanoids (F2-isoprostanes) are formed in situ on phospholipids. Proc Natl Acad Sci U S A. 1992;89:10721-5.

Myatt L. Review: reactive oxygen and nitrogen species and functional adaptation of the placenta. Placenta. 2010;31(Suppl): S66-9.

Myatt L, Cui X. Oxidative stress in the placenta. Histochem Cell Biol. 2004;122:369-82.

Nasr A. Effect of N-acetyl-cysteine after ovarian drilling in clomiphene citrate-resistant PCOS women: a pilot study. Reprod Biomed Online. 2010;20:403-9.

Polak G, Kotarski J. Total oxidative status of peritoneal fluid in women with endometriosis. Ginekol Pol. 2010;81:922-5.

Polak G, Rola R, Gogacz M, Kozioł-Montewka M, Kotarski J. Malonyldialdehyde and total antioxidant status in the peritoneal fluid of infertile women. Ginekol Pol. 1999;70:135-40.

Polak G, Kozioł-Montewka M, Gogacz M, Błaszkowska I, Kotarski J. Total antioxidant status of peritoneal fluid in infertile women. Eur J Obstet Gynecol Reprod Biol. 2001a;94:261-3.

Polak G, Kozioł-Montewka M, Tarkowski R, Kotarski J. Peritoneal fluid and plasma 4-hydroxynonenal and malonyldialdehyde concentrations in infertile women. Ginekol Pol. 2001b;72:1316-20.

Poli G, Leonarduzzi G, Biasi F, Chiarpotto E. Oxidative stress and cell signalling. Curr Med Chem. 2004;11:1163-82.

Poston L, Raijmakers MT. Trophoblast oxidative stress, antioxidants and pregnancy outcome-a review. Placenta. 2004;25(A):S72-8.

Poston L, Igosheva N, Mistry HD, Seed PT, Shennan AH, Rana S, et al. Role of oxidative stress and antioxidant supplementation in pregnancy disorders. Am J Clin Nutr. 2011;94:1980S$5 \mathrm{~S}$.

Radomski D, Orzechowska A, Barcz E. Present conceptions of etiopathogenesis of polycystic ovary syndrome. Ginekol Pol. 2007;78:393-9.

Raijmakers MT, Dechend R, Poston L. Oxidative stress and preeclampsia: rationale for antioxidant clinical trials. Hypertension. 2004;44:374-80.

Rizk AY, Bedaiwy MA, Al-Inany HG. N-acetyl-cysteine is a novel adjuvant to clomiphene citrate in clomiphene citrate-resistant patients with polycystic ovary syndrome. Fertil Steril. 2005;83:367-70.
Roberts JM, August PA, Bakris G, Barton JR, Bernstein IM, Druzin $M$, et al. Hypertension in pregnancy. Report American College Obstetricians Gynecologists' Task Force Hypertension Pregnancy. Obstet Gynecol. 2013;122(5): 1122-31.

Rong R, Ramachandran S, Santanam N, Murphy AA, Parthasarathy S. Induction of monocyte chemotactic protein-1 in peritoneal mesothelial and endometrial cells by oxidized low-density lipoprotein and peritoneal fluid from women with endometriosis. Fertil Steril. 2002;78:843-8.

Roos N, Kieler H, Sahlin L, Ekman-Ordeberg G, Falconer H, Stephansson O. Risk of adverse pregnancy outcomes in women with polycystic ovary syndrome: population based cohort study. BMJ. 2011;343:d6309.

Ruder EH, Hartman TJ, Blumberg J, Goldman MB. Oxidative stress and antioxidants: exposure and impact on female fertility. Hum Reprod Update. 2008;14:345-57.

Rumbold, A., P. Middleton, and C.A. Crowther. Vitamin supplementation for preventing miscarriage. Cochrane Database Syst Rev. 2005;CD004073.

Sacks DA, Hadden DR, Maresh M, Deerochanawong C, Dyer AR, Metzger BE, et al. Frequency of gestational diabetes mellitus at collaborating centers based on IADPSG consensus panel-recommended criteria: the Hyperglycemia and Adverse Pregnancy Outcome (HAPO) Study. Diabetes Care. 2012;35:526-8.

Sakamaki H, Akazawa S, Ishibashi M, Izumino K, Takino H, Yamasaki H, et al. Significance of glutathione-dependent antioxidant system in diabetes-induced embryonic malformations. Diabetes. 1999;48:1138-44.

Salehpour S, Sene AA, Saharkhiz N, Sohrabi MR, Moghimian F. $\mathrm{N}$-acetylcysteine as an adjuvant to clomiphene citrate for successful induction of ovulation in infertile patients with polycystic ovary syndrome. J Obstet Gynaecol Res. 2012;38:1182-6.

Salmon AB, Richardson A, Pérez VI. Update on the oxidative stress theory of aging: does oxidative stress play a role in aging or healthy aging? Free Radic Biol Med. 2010;48:64255 .

Santanam N, Kavtaradze N, Murphy A, Dominguez C, Parthasarathy S. Antioxidant supplementation reduces endometriosis-related pelvic pain in humans. Transl Res. 2013;161:189-95.

Scifres CM, Nelson DM. Intrauterine growth restriction, human placental development and trophoblast cell death. J Physiol. 2009;587:3453-8.

Sharma I, Dhaliwal LK, Saha SC, Sangwan S, Dhawan V. Role of 8-iso-prostaglandin F2alpha and 25-hydroxycholesterol in the pathophysiology of endometriosis. Fertil Steril. 2010;94:63-70.

Shibata M, Hakuno F, Yamanaka D, Okajima H, Fukushima T, Hasegawa T, et al. Paraquat-induced oxidative stress represses phosphatidylinositol 3-kinase activities leading to impaired glucose uptake in 3T3-L1 adipocytes. J Biol Chem. 2010;285:20915-25.

SHUTE EV. Should spontaneous abortion be prevented? Vitamin E in its management. Can Med Assoc J. 1960;82:72-6.

Silva E, Soares-da-Silva P. Reactive oxygen species and the regulation of renal Na+-K+-ATPase in opossum kidney cells Am J Physiol Regul Integr Comp Physiol. 2007;293:R176470. 
Simán CM, Eriksson UJ. Vitamin C supplementation of the maternal diet reduces the rate of malformation in the offspring of diabetic rats. Diabetologia. 1997a;40:1416-24.

Simán CM, Eriksson UJ. Vitamin E decreases the occurrence of malformations in the offspring of diabetic rats. Diabetes. 1997b;46:1054-61.

Sugimura Y, Murase T, Kobayashi K, Oyama K, Hayasaka S, Kanou Y, et al. Alpha-lipoic acid reduces congenital malformations in the offspring of diabetic mice. Diabetes Metab Res Rev. 2009;25:287-94.

Takagi Y, Nikaido T, Toki T, Kita N, Kanai M, Ashida T, et al. Levels of oxidative stress and redox-related molecules in the placenta in preeclampsia and fetal growth restriction. Virchows Arch. 2004;444:49-55.

Tarín JJ, Pérez-Albalá S, Cano A. Consequences on offspring of abnormal function in ageing gametes. Hum Reprod Update. 2000;6:532-49.

Theuerkauf RS, Ahammer H, Siwetz M, Helige C, Dohr G, Walcher W, et al. Measurement of cell death by oxidative stress in three-dimensional spheroids from trophoblast and in fragments of decidua tissue. J Reprod Immunol. 2010;85:6370.

Tuuli MG, Longtine MS, Nelson DM. Review: oxygen and trophoblast biology - a source of controversy. Placenta. 2011;32 Suppl 2:S109-18.
Valko M, Leibfritz D, Moncol J, Cronin MT, Mazur M, Telser J. Free radicals and antioxidants in normal physiological functions and human disease. Int J Biochem Cell Biol. 2007;39: 44-84.

Victor VM, Rocha M, Bañuls C, Alvarez A, de Pablo C, SanchezSerrano M, et al. Induction of oxidative stress and human leukocyte/endothelial cell interactions in polycystic ovary syndrome patients with insulin resistance. J Clin Endocrinol Metab. 2011;96:3115-22.

Wang Y, Sharma RK, Falcone T, Goldberg J, Agarwal A. Importance of reactive oxygen species in the peritoneal fluid of women with endometriosis or idiopathic infertility. Fertil Steril. 1997;68:826-30.

Wentzel P, Eriksson UJ. A diabetes-like environment increases malformation rate and diminishes prostaglandin $\mathrm{E}(2)$ in rat embryos: reversal by administration of vitamin $\mathrm{E}$ and folic acid. Birth Defects Res A Clin Mol Teratol. 2005;73:506-11.

Wiktor H, Kankofer M, Schmerold I, Dadak A, Lopucki M, Niedermüller H. Oxidative DNA damage in placentas from normal and pre-eclamptic pregnancies. Virchows Arch. 2004;445:74-8.

Yessoufou A, Soulaimann N, Merzouk SA, Moutairou K, Ahissou $\mathrm{H}$, Prost J, et al. N-3 fatty acids modulate antioxidant status in diabetic rats and their macrosomic offspring. Int $\mathbf{J}$ Obes (Lond). 2006;30:739-50. 